\title{
Comparing manual and mechanically assisted manipulations of the thoracic spine in neck pain patients: A pilot study
} [version 1; peer review: 1 not approved]

\author{
Anke Langenfeld (D1,2, B. Kim Humphreys², Rob A. de Bie1, Jaap Swanenburg 2,3 \\ ${ }^{1}$ Department of Epidemiology and CAPHRI School for Public Health and Primary Care, Maastricht University, Maastricht, 6229 ER, \\ The Netherlands \\ ${ }^{2}$ Interdisciplinary Spinal Research ISR, Department of Chiropractic Medicine, Balgrist University Hospital, Zürich, 8008, Switzerland \\ ${ }^{3}$ Physiotherapy Occupational Therapy Research Centre, University Hospital Zurich, Zürich, 8091, Switzerland
}

V1 First published: 07 Feb 2018, 7:156

https://doi.org/10.12688/f1000research.13780.1

Latest published: 07 Feb 2018, 7:156

https://doi.org/10.12688/f1000research.13780.1

\section{Abstract}

Background: Manipulations of the thoracic spine are a common treatment option in patients with neck pain. This approach avoids the risk of cervical arterial dissection. Currently there are different options available which have been evaluated for their efficacy. The aim of this study was to assess short- and long-term effects of two different methods of manipulating the thoracic spine in combination with a standardized exercise program for neck pain.

Methods: This pilot study included patients who were over 18 years of age, able to speak and read German or English, had acute or chronic neck pain, and had not previously undergone manual therapy for the thoracic spine. Patients were recruited from private physical therapy practices. Patients were randomly assigned to two treatment groups by using block randomization. The objective was to compare the effects of manually performed manipulations and electromechanical manipulations on the thoracic spine in patients with neck pain. Primary outcome was the visual analogue pain rating scale. Secondary outcomes included Neck Disability Index, European Quality of Life scale, and Patients' Global Impression of Change Scale.

Results: Ten patients were recruited. Five patients received manual manipulations, and five received electromechanical manipulations. Both groups showed an improvement in pain scores (VAS) $\left(X^{2}(5)=\right.$ $14.161, p=0.015)$ with no difference between the groups. There were no significant changes in the secondary outcomes. The electromechanical (Impulse iQ ${ }^{\circledR}$ ) manipulations group showed a clinically relevant reduction in the neck disability index.

Conclusion: Both manual and electromechanical manipulations are well tolerated, and show that they can be both successful treatments for neck pain in combination with exercises. Thoracic manipulations seem to be beneficial for the patient's complaint of neck pain, while

\section{Peer review discontinued \\ Peer review at F1000Research is author- driven. Currently no reviewers are being invited. What does this mean?}

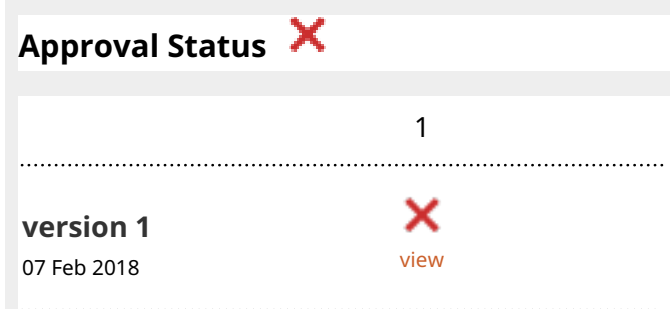

1. Arianne P. Verhagen (D), University of

Technology Sydney, Sydney, Australia

Any reports and responses or comments on the article can be found at the end of the article. 
electromechanical manipulations seem to be able to reduce neck

disability.

Trial registration: Current Controlled Trials ISRCTN88585962,

registered in January 2013.

Keywords

Manipulation, Manual, Electromechanical, Thoracic spine, Neck pain

Corresponding author: Anke Langenfeld (ankelangenfeld@googlemail.com)

Author roles: Langenfeld A: Conceptualization, Funding Acquisition, Investigation, Methodology, Project Administration, Visualization, Writing - Original Draft Preparation; Humphreys BK: Conceptualization, Methodology, Supervision, Writing - Review \& Editing; de Bie RA: Conceptualization, Methodology, Supervision, Writing - Review \& Editing; Swanenburg J: Conceptualization, Data Curation, Formal Analysis, Investigation, Methodology, Project Administration, Resources, Supervision, Writing - Original Draft Preparation

Competing interests: No competing interests were disclosed.

Grant information: The author(s) declared that no grants were involved in supporting this work.

Copyright: ( $) 2018$ Langenfeld A et al. This is an open access article distributed under the terms of the Creative Commons Attribution License, which permits unrestricted use, distribution, and reproduction in any medium, provided the original work is properly cited. Data associated with the article are available under the terms of the Creative Commons Zero "No rights reserved" data waiver (CC0 1.0 Public domain dedication).

How to cite this article: Langenfeld A, Humphreys BK, de Bie RA and Swanenburg J. Comparing manual and mechanically assisted manipulations of the thoracic spine in neck pain patients: A pilot study [version 1; peer review: 1 not approved] F1000Research 2018, 7:156 https://doi.org/10.12688/f1000research.13780.1

First published: 07 Feb 2018, 7:156 https://doi.org/10.12688/f1000research.13780.1 


\section{Introduction}

Neck pain ranks fourth among the most common musculoskeletal complaints worldwide ${ }^{1}$. Although often not disabling, most patients with neck pain will not experience a complete resolution of their problem ${ }^{2}$. Furthermore, various possible causes for neck pain exist ${ }^{2}$. Neck pain symptoms are often temporary and can be treated successfully with nonsurgical care such as medication, physical therapy, and manipulations ${ }^{3-5}$. Best studied treatments are cervical spine manipulations in conjunction with exercise therapy ${ }^{6,7}$. Although there is conflicting evidence, cervical spinal manipulations are suspected to cause serious adverse events such as cervical artery dissection (CAD) (see The International Federation of Orthopaedic Manipulative Physical Therapists (IFOMPT) cervical framework $)^{8-11}$. An alternative approach to cervical manipulations, which has been reviewed extensively, is manipulations of the thoracic spine ${ }^{12-23}$.

Manipulations may be delivered either manually (high velocity low amplitude) or mechanically using different spring-loaded or electromechanical devices ${ }^{24-27}$. However, manual forces given by the same practitioner may vary somewhat for each manipulation session and between practitioners ${ }^{28}$. Forces applied by an electromechanical device are more consistent ${ }^{24}$. Thus far, only three studies have compared between manual and mechanical manipulations ${ }^{26,27,29}$. In 2001, Wood and colleagues evaluated neck pain patients. They compared mechanical force, manually assisted (MFMA) adjustments (activator II adjusting instrument) to high velocity, and low-amplitude manipulation directed to a dysfunctional cervical spinal motion unit ${ }^{26}$. Shearar et al. (2005) evaluated patients with recent low back pain who were diagnosed with sacroiliac joint syndrome at the initial assessment. Patients were either treated with manually delivered chiropractic adjustments or an MFMA adjustment using an activator adjusting instrument ${ }^{27}$.

Schneider et al. worked with acute low back pain patients in which one group received treatment by activator method proficiency-certified chiropractors while the other two groups used side posture thrust manipulation ${ }^{29}$. The abovementioned studies suggest that both ways of delivering manipulations are beneficial to reduce the patients' pain and disability. The latest technical development of such an electromechanical device, the Impulse $\mathrm{iQ}{ }^{\circledR}$, incorporates a feedback loop to adjust the manipulation force to the resonance of the patient's spine. Yet, no studies have investigated the effectiveness of this device.

The objective of our pilot study was to compare short- and long-term effects of two different ways of manipulating the thoracic spine in combination with a standardized exercise program for neck pain.

\section{Methods}

Study design

A pilot study was conducted to compare the effects of two different methods of manipulation (manual manipulation vs. electromechanical manipulation) on the thoracic spine for patients with neck pain. A complete study protocol for a randomized controlled trial was published in May $2015^{30}$. The study received ethical approval from the Ethics Commission of the Canton of Zurich (2012-0248) and was registered at Current Controlled Trials (ISRCTN88585962). A completed CONSORT checklist can be found in Supplementary File 1.

\section{Participants}

Every participant received all relevant patient information in advance. When a potential participant had read the information and was willing to participate, he or she signed the informed consent form. Participants were recruited from, May 2013 until August 2015, in private physical therapy practices in Zurich, Switzerland. Inclusion criteria were the presence of acute or chronic neck pain grade $\mathrm{I}$ or $\mathrm{II}^{31}$, age 18 years or older, able to speak and read German or English, no previous manual therapy of the thoracic spine, and interest in participating in the study.

Patients were excluded if they had severe disorders of the cervical spine, such as disk prolapse, spinal stenosis, postoperative conditions in neck and shoulder areas, a history of severe trauma, spasmodic torticollis, frequent migraine headaches, peripheral nerve entrapment, fibromyalgia, shoulder diseases (causing reduced mobility of the joint, e.g., fractures, adhesive capsulitis), inflammatory rheumatic diseases, osteoporosis, or cancer or if they were currently undergoing legal procedures related to their neck pain.

Additional evaluations (history taking and physical examination) of the participant were added after baseline measurements to confirm eligibility of the participant to be included in the study population $^{30}$.

\section{Randomization}

A clinician not involved in the study randomized the participants independently into one of the two groups. Block randomization (20 blocks of 4) was carried out using a computer-based randomization program. The original list was stored in an opaque and sealed envelope, not accessible to the therapist delivering the manipulations. To reduce intervention bias, 80 individually numbered opaque and sealed envelopes were prepared, and the therapist received the assigned envelope immediately before each participant was to receive the manipulation. Additionally, after the participants completed the questionnaires, they were put into an opaque envelope that was individually and immediately sealed by the patient. The therapist was unaware of the outcome. The anonymous data were entered into the database and were untraceable to the participating patient.

\section{Intervention}

Each patient underwent three treatment sessions, with 4 days interval between each session. Additionally, during the first session, all participants were instructed to participate in an exercise program, which was to be completed as soon as possible. To evaluate compliance of the participants, they received a journal and were asked to mark the days that they had completed the required exercises. Follow-up assessments were conducted at 6 weeks, 3 months, and 6 months after the initial treatment. 
Patients received the questionnaires by mail, including prepaid envelopes, to facilitate return of the completed forms. An extensive explanation of the treatments can be found elsewhere ${ }^{30}$.

\section{Manual manipulations}

For the manually performed manipulations, the patient was supine. The therapist's hand was placed under the thoracic spine using a pistol grip (the fingers positioned with the index finger straightened and fingers 3 to 5 flexed). The patient's forearms were crossed in front of their chest. The force was applied against the therapist's flexed fingers and the thenar eminence and slightly cranial to the transverse process of the caudal vertebrae of the segment to be treated ${ }^{32}$.

\section{Electromechanical manipulations}

For the electromechanical manipulations, the Impulse $\mathrm{iQ}{ }^{\circledR}$ (Neuromechanical Innovations, Chandler, AZ, USA) was used. The patient was prone on a treatment table, with arms parallel to the body, in a relaxed position. Before the treatment began, the patient was instructed that they would hear a rattling sound that indicated the treatment thrusts conducted by the device and a beep to signify the end of treatment. The Impulse iQ was placed onto the vertebrae previously identified as the painful segment. A double stylus and middle force setting (peak force $=200 \mathrm{~N}$ ), as recommended by the manufacturer for the treatment of the thoracic spine, was used ${ }^{33}$. The device recorded and analyzed the spinal acceleration response each time a thrust was delivered by using the in-built firmware. To begin, the machine produced a series of repetitive thrusts while monitoring the acceleration response. If the response improved, the treatment thrusts continued up to 3 more seconds. If the acceleration response was negative (flat line or decrease), the thrusts delivered by the instrument ceased.

\section{Exercise program}

After the first treatment session, all patients were introduced to the home exercise program and asked to perform this program once a day for 6 weeks. Compliance with the home exercise program was assessed using a training journal as follows: (1) retraining the craniocervical muscles (e.g., training the holding capacity of the deep neck flexors and head lift), (2) retraining the scapular muscles, and (3) eye/head coordination ${ }^{34,35}$. For a complete overview of the study`s course see Figure 1.

\section{Outcome measures}

Baseline measures included age, weight, height, and the European Quality of Life 5 Dimensions 5 Levels (EQ-5D-5L). Furthermore, each patient's expectation of treatment outcome (the treatment he or she expected to be more beneficial) was assessed at the beginning of the study. The primary outcome measure was the Visual Analogue Pain rating scale (VAS) that assesses pain intensity level ${ }^{36-39}$. The VAS was completed before and after every treatment session and at all follow-up points. Secondary outcomes were the Neck Disability Index (NDI) and the Patients Global Impression of Change Scale (PGIC) $)^{40-44}$.

The NDI is a self-reported questionnaire to evaluate disability. It consists of 10 items that score from zero to five. The higher the total score, the higher is the disability level of the patient ${ }^{41}$. The NDI's minimal clinical important difference (MCID) in patients with neck pain ranges from 3.5 to 9.5 , which mainly depends on the patient characteristics ${ }^{45-47}$. Pereira et al. (2015) state that in patients with chronic neck pain, the score has to be above 5.5 points, otherwise it is clinically irrelevant ${ }^{45,48,49}$. Before the second, third treatments and all follow-up assessment, the patients were asked about their global impression of change, using the PGIC $^{50}$. The PGIC is a valid outcome measure that is based on a seven-point Likert scale ${ }^{51}$. Its purpose is to obtain a patient's report of improvement over time during treatment. The scale ranges from much better, better, somewhat better, no change, somewhat worse, worse, and much worse. Much better is rated as 7 and much worse as $1^{44}$. It can be used to dichotomize participants into two groups: improved (ratings of 6 and 7) and not improved (ratings 1 to 5).

\section{Statistics}

The data were stored and analyzed using the IBM SPSS 21 statistical software package (SPSS, Inc., Chicago, IL). Descriptive statistics were used to describe patient characteristics. Collected data were checked for normal distribution using the Shapiro-Wilk Test. The test identified that the scores for VAS and NDI were normally distributed. Because of outliers, the Friedman test was used as a nonparametric statistical test to retain all data points. The goal was to determine whether there were any statistically significant differences between the distributions of three or more related groups. Furthermore, pairwise comparisons were performed (SPSS Statistics, 2012) with a Bonferroni correction for multiple comparisons.

\section{Results}

The study included two male and eight female participants. Because of unknown causes, one participant dropped out of the study after the first treatment. Nine participants had experienced chronic neck pain problems ( $>90$ days), and one patient had acute problems ( $<90$ days) (please see Table 4). Two participants had co-morbidities such as low back pain and coccydynia. Six participants believed that the conventional (manual) manipulation would be more successful, while four believed the electromechanical manipulation would be superior. Five participants received a manual treatment, and the remaining five received an electromechanical treatment. Three participants identified the third thoracic vertebra as the most painful and two identified the seventh thoracic vertebra. The second, fourth, fifth, sixth, and the tenth thoracic vertebrae were named by one patient as the most painful ones. Table 1 presents the demographic data and baseline measurements.

\section{Primary outcome}

Both groups showed a significant improvement in pain scores (Friedman test, VAS X $\left.X^{2}(5)=14.161, p=0.015\right)$. There were no statistically significantly differences between the two treatment groups: electromechanical $\mathrm{X}^{2}(5)=7.701, p=0.174 /$ manual $\mathrm{X}^{2}(5)=7.774, p=0.169$. Bonferroni correction post hoc analysis revealed statistical differences in the rating from follow-up measurements at 3 months (median $=6.00$ ) from the first appointment $($ median $=26.00)(p=0.008)$. VAS scores at the 


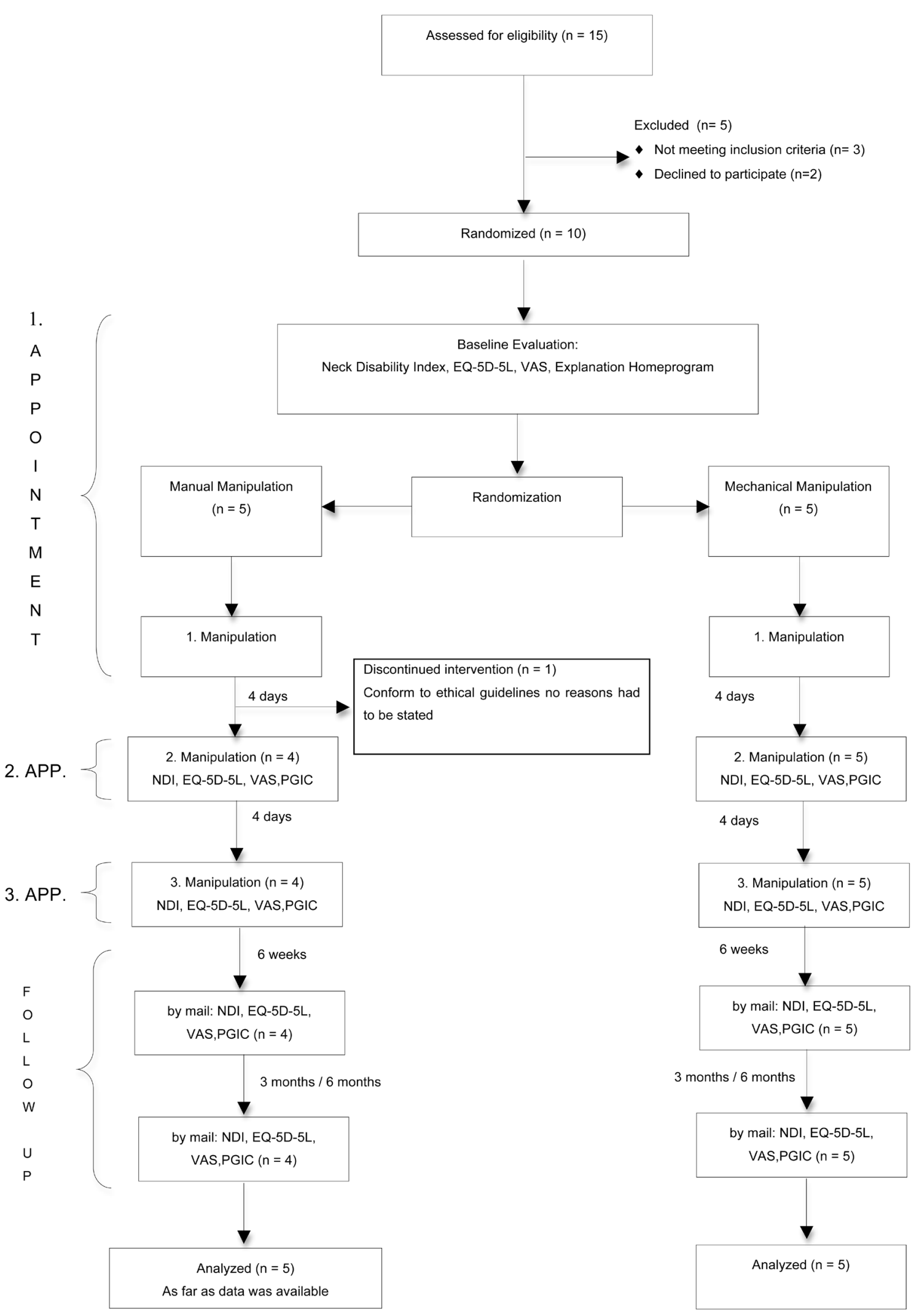

Flowchart_Pilot_AL_14.10.2016

Figure 1. Flowchart of the trial, describing the process of randomization, evaluation and treatment. 
baseline reduced by $11 \%$ at second treatment, $27 \%$ at third treatment, $54 \%$ after 6 weeks, $77 \%$ after 3 months, and $42 \%$ after 6 months. The $\%$ change of pain is shown in Table 2.

\section{Secondary outcome}

Because of outliers, the Friedman test was used for analyzing the NDI. There was no significant change $\left(X^{2}(5)=10.562\right.$, $p=0.061)$. No significant change in NDI was observed between the two groups (electromechanical $X^{2}(5)=5.234$, $p=0.388 /$ manual group $\left.\mathrm{X}^{2}(5)=5.546, p=0.232\right)$. The change over time (median) is shown in Table 3.

PGIC

After the first treatment, four out of nine patients rated themselves as improved, five patients after the second treatment, three patients after 6 weeks, two patients after 3 months, and three patients after 6 months. All other participants stated that they had no improvement, but the pain did not get worse. In total, there were 10 ratings of improvement in the electromechanical manipulation group and 7 in the manual manipulation group (see Table 4 for a detailed rating).

\section{Additional interventions}

Overall, four participants had additional treatment during the 6 months of follow-up. After 3 months of treatment, two participants visited a physical therapist and one participant received acupuncture once a week. At the 6 months survey, another participant received chiropractic treatment (three times) and one continued to visit a physical therapist, if the neck pain was too severe.

Dataset 1. Complete set of all data recorded as part of this pilot study

http://dx.doi.org/10.5256/f1000research.13780.d192478

Table 1. Demographic Data and Baseline Measurements.

\begin{tabular}{|c|c|c|c|c|c|}
\hline & N & Minimum & Maximum & Mean & $\begin{array}{c}\text { Standard } \\
\text { Deviation }\end{array}$ \\
\hline Age (y) & 10 & 21 & 72 & 50.50 & 16.88 \\
\hline Height $(\mathrm{cm})$ & 10 & 145.0 & 193.0 & 166.40 & 13.05 \\
\hline Weight $(\mathrm{kg})$ & 10 & 50.0 & 91.0 & 69.63 & 13.80 \\
\hline VAS (mm) & 10 & 5 & 51 & 27.70 & 13.54 \\
\hline NDI-G & 10 & 3 & 15 & 10.20 & 3.5 \\
\hline EQ-5D-5L & 8 & 0.72 & .091 & 0.87 & 0.069 \\
\hline EQ-5D-5L-1VAS & 10 & 20 & 95 & 71.50 & 23.22 \\
\hline
\end{tabular}

Table 2. Visual Analogue Pain Rating Scale (VAS) and \% change over a period of 6 months in all participants.

\begin{tabular}{|c|c|c|c|c|c|c|}
\hline \multirow[t]{3}{*}{ Manipulation } & \multicolumn{6}{|c|}{ VAS } \\
\hline & \multicolumn{3}{|c|}{ Treatment } & \multicolumn{3}{|c|}{ Follow up } \\
\hline & 1 & 2 & 3 & 6 weeks & 3 months & 6 months \\
\hline All (Change \%) & 26.00 & $23.00(-11 \%)$ & $19.00(-27 \%)$ & $12.00(-54 \%)$ & $6.00(-77 \%)$ & $15.00(-42 \%)$ \\
\hline Electromechanical Group & 17.00 & $19.50(+14 \%)$ & $13.00(-23 \%)$ & $10.00(-41 \%)$ & $5.50(-68 \%)$ & $13.00(-28 \%)$ \\
\hline Manual Group & 26.00 & $25.00(-4 \%)$ & $19.00(-27 \%)$ & $12.00(-54 \%)$ & $15.50(-40 \%)$ & $15.00(-42 \%)$ \\
\hline
\end{tabular}

Table 3. Median of the Neck Disability Index (NDI) and \% change score over a period of 6 months.

\begin{tabular}{|c|c|c|c|c|c|c|}
\hline Manipulation & NDI 1 & NDI 2 & NDI 3 & NDI 6 weeks & NDI 3 month & NDI 6 month \\
\hline $\begin{array}{c}\text { All } \\
\text { (Change \%) }\end{array}$ & 10.5 & $\begin{array}{c}6.00 \\
(-43 \%)\end{array}$ & $\begin{array}{c}7.00 \\
(-33 \%)\end{array}$ & $\begin{array}{c}7.00 \\
(-33 \%)\end{array}$ & $\begin{array}{c}6.50 \\
(-38 \%)\end{array}$ & $\begin{array}{c}6.00 \\
(-43 \%)\end{array}$ \\
\hline Electromechanical Group & 11.00 & $\begin{array}{c}6.00 \\
(-55 \%)\end{array}$ & $\begin{array}{c}6.85 \\
(-38 \%)\end{array}$ & $\begin{array}{c}5.50 \\
(-50 \%)\end{array}$ & $\begin{array}{c}5.50 \\
(-50 \%)\end{array}$ & $\begin{array}{c}7.00 \\
(-36 \%)\end{array}$ \\
\hline Manual Group & 10.00 & $\begin{array}{c}6.00 \\
(-40 \%)\end{array}$ & $\begin{array}{c}7.00 \\
(-30 \%)\end{array}$ & $\begin{array}{c}7.00 \\
(-30 \%)\end{array}$ & $(-25 \%)$ & $(-50 \%)$ \\
\hline
\end{tabular}


Table 4. Overview of PGIC outcome, expectation of favourable treatment and additional treatment (chiropractic, physical therapy [PT], and acupuncture), and duration of complaints. The numbers in bold represent the patients that reported improvement (value greater than 5 ).

\begin{tabular}{|c|c|c|c|c|c|c|c|c|}
\hline & $\begin{array}{c}\text { PGIC } \\
\text { (after } \\
\text { the first } \\
\text { treatment) }\end{array}$ & $\begin{array}{c}\text { PGIC } \\
\text { (after the } \\
\text { second } \\
\text { treatment) }\end{array}$ & $\begin{array}{l}\text { PGIC at } \\
6 \text { weeks }\end{array}$ & $\begin{array}{c}\text { PGIC at } \\
\text { three } \\
\text { months }\end{array}$ & $\begin{array}{c}\text { PGIC } \\
\text { at six } \\
\text { months }\end{array}$ & Expectation & $\begin{array}{l}\text { Additional } \\
\text { treatment }\end{array}$ & $\begin{array}{l}\text { Duration of } \\
\text { complaints }\end{array}$ \\
\hline Participant $1^{(\mathrm{iQ})}$ & 6 & 6 & 4 & 5 & 6 & Manual & No & >90 days \\
\hline Participant $2^{(\mathrm{iQ})}$ & 4 & 5 & 5 & 5 & 2 & Manual & 3x Chiropractic & >90 days \\
\hline Participant $4^{(\mathrm{iQ})}$ & 5 & 6 & 6 & 5 & 7 & iQß & No & 42 days \\
\hline Participant $5^{(\mathrm{iQ})}$ & 4 & 4 & 4 & 6 & 4 & Manual & No & >90 days \\
\hline Participant $6^{\text {(manual) }}$ & 6 & 6 & 7 & 7 & 7 & $\mathrm{iQR}$ & No & >90 days \\
\hline Participant $7^{\text {(manual) }}$ & 4 & 4 & 5 & 5 & 4 & $\mathrm{iQR}$ & No & >90 days \\
\hline Participant $8^{\text {(manual) }}$ & 6 & 6 & 6 & 5 & 4 & iQß & $3 \times \mathrm{PT}$ & >90 days \\
\hline Participant 9(manual) & 4 & 4 & 4 & 4 & 4 & iQß & PT & >90 days \\
\hline Participant $10^{\text {(manual) }}$ & 6 & 6 & 5 & 5 & 5 & Manual & Acupuncture & >90 days \\
\hline
\end{tabular}

\section{Discussion}

The main goal of our pilot study was to compare short- and long-term effects of two different ways of manipulating the thoracic spine in combination with a standardized exercise program for patients with a main complaint of neck pain. In this study, the main outcome was pain intensity using the VAS. We found a significant reduction in neck pain for all patients, but not between the groups. Additionally, there was a tendency and a clinically relevant decrease in neck disability in accordance with the report of Pereira and colleagues that state a reduction of 5.5 points on the NDI in patients with chronic neck pain is a minimal clinically important difference ${ }^{49}$. In particular, the electromechanical group showed a decrease in their VAS scoring of 5.5 after 6 weeks and after 3 months. Although this did not reach statistical significance, we were able to show a tendency for improvement in this group.

However, a wear off in VAS reduction was observed at 6 months. The follow-up of 6 months could have been too long. Patients may have forgotten the details of the interventions. Four of the patients had additional therapy during the follow-up period. Since our groups were small, this might have influenced the outcomes. One suggestion for further research is to use a paper-based or electronic diary to report all possible relevant incidents and interventions ${ }^{52,53}$.

To our knowledge this is the first study that investigated the short- and long-term outcome of electromechanical manipulation. None of the other studies, which were identified during literature review, assessed long-term outcomes of a device with a feedback loop ${ }^{26,27,29}$. Other studies had a follow-up period that lasted only 4 weeks $^{28}$. Huggins and colleagues (2012) postulated the need for more studies evaluating activator adjusting instruments and their long-term outcomes ${ }^{54}$. Patients from previous studies received more treatment than those in our study. Our study had three treatment sessions as recommended by former clinical prediction guidelines ${ }^{55}$. Wood et al. (2001) and Schneider et al. (2011) had eight treatments sessions in 4 weeks ${ }^{26,29,58}$. Shearar et al. (2005) used four treatments over a 2 -week period ${ }^{27}$. Even with the fewer treatment sessions, we could reduce pain significantly. However, in this study, an important difference compared to the other studies is the addition of exercises with the spinal manipulation treatment. The combination of exercise and manipulation is currently the best evidence-based approach for neck pain ${ }^{6,7}$.

One important reason for conducting this study relates to the question on cervical spinal manipulation and serious adverse events such as cervical artery dissection. (see Australian Physiotherapy Association guidelines for vertebrobasilar insufficiency $)^{8,56}$. There is a debate in the literature referring to these events, and this serious complication should be considered if a patient is going to be treated with cervical spinal manipulation (see Australian Physiotherapy Association guidelines for vertebrobasilar insufficiency) $)^{8,57-63}$. In our study, no serious adverse events occurred. This suggests the treatment of patients with neck pain by manual or electromechanical manipulation of the thoracic spine may provide another treatment option.

From the findings of our pilot study, we calculated the sample size for each time point of a RCT by using the formula $2 \times[(1.96+$ $\left.0.842)^{2} \times \mathrm{SD}^{2}\right] / 12^{264,65}$. The calculation revealed that a sample size of 20 per treatment arm at the first time point would be sufficient to show significant differences in outcomes. However, the sample size requirements increased to 24 participants at 6 weeks and 57 participants at 6 months. For a two group pre-test / post-test / follow-up design, a total sample size of 114 participants will be sufficient to reach result with $80 \%$ power at an $\alpha$-level of 0.05 . 


\section{Limitation}

One obvious limitation was the small sample size of the study. One recruitment problem was to find patients who had not received previous manual therapy. Recruitment of chronic patients who were not already treated for their pain condition was therefore especially difficult. Furthermore, our exercise program was not tailored to the individual needs of every patient. This could have influenced the outcome because patients might have needed a more individualized exercise program to approach to their problem, although recent literature suggest, that an individualized treatment is not always superior ${ }^{66}$. Nevertheless, we could show that pain decreased during the intervention.

\section{Conclusion}

Neck pain can be influenced by manipulations applied to the thoracic spine in combination with exercise therapy. Additionally, our study suggests that electromechanical manipulations may be able to decrease neck disability. However, caution is advised concerning these results because of the study's small sample size. The findings of this pilot study allowed the power calculation of the actual sample size needed for a larger randomized controlled trial aimed at studying manipulations applied to the thoracic spine in combination with exercise therapy in patients with neck pain.

\section{Data availability}

Dataset 1: Complete set of all data recorded as part of this pilot study. File name - manual vs mechanically_RCT_f1000 10.5256/ f1000research.13780.d192478

\section{Ethics approval}

The study received ethical approval from the Ethics Commission of the Canton of Zurich (2012-0248) and was registered at Current Controlled Trials (ISRCTN88585962).

\section{Competing interests}

No competing interests were disclosed.

\section{Grant information}

The author(s) declared that no grants were involved in supporting this work.

\section{Acknowledgments}

The Impulse IQ ${ }^{\circledR}$ was provided by Neuromechanical Innovations, Chandler, AZ, USA.

A disclaimer response was written and signed before the start of the study.

\section{Supplementary material}

Supplementary File 1: Completed CONSORT checklist.

Click here to access the data.

1. Global Burden of Disease Study 2013 Collaborators: Global, regional, and national incidence, prevalence, and years lived with disability for 301 acute and chronic diseases and injuries in 188 countries, 1990-2013: a systematic analysis for the Global Burden of Disease Study 2013. Lancet. 2015; 386(9995): 743-800.

PubMed Abstract | Publisher Full Text | Free Full Text

2. Haldeman S, Carroll L, Cassidy JD, et al:: The Bone and Joint Decade 2000-2010 Task Force on Neck Pain and Its Associated Disorders: executive summary.

J Manipulative Physiol Ther. 2009; 32(2 Suppl): S7-9.

PubMed Abstract | Publisher Full Text

3. Hurwitz EL, Carragee EJ, van der Velde G, et al:: Treatment of neck pain: noninvasive interventions: results of the Bone and Joint Decade 2000-2010 Task Force on Neck Pain and Its Associated Disorders. J Manipulative Physiol Ther 2009; 32 (2 Suppl): S141-75. PubMed Abstract | Publisher Full Text

4. Varatharajan S, Ferguson B, Chrobak K, et al.: Are non-invasive interventions effective for the management of headaches associated with neck pain? An update of the Bone and Joint Decade Task Force on Neck Pain and Its Associated Disorders by the Ontario Protocol for Traffic Injury Management (OPTIMa) Collaboration. Eur Spine J. 2016; 25(7): 1971-99. PubMed Abstract | Publisher Full Text

5. Gross A, Langevin P, Burnie SJ, et al:: Manipulation and mobilisation for neck pain contrasted against an inactive control or another active treatment. Cochrane Database Syst Rev. 2015; (9): CD004249. PubMed Abstract | Publisher Full Text
6. Wong JJ, Shearer HM, Mior S, et al:: Are Manual Therapies, Passive Physical Modalities, or Acupuncture Effective for the Management of Patients with Whiplash-Associated Disorders or Neck Pain and Associated Disorders? An Update of the Bone and Joint Decade Task Force on Neck Pain and Its Ass. Elsevier Inc.; 2015. Reference Source

7. Côté $P$, Wong JJ, Sutton D, et al:: Management of neck pain and associated disorders: A clinical practice guideline from the Ontario Protocol for Traffic Injury Management (OPTIMa) Collaboration. Eur Spine J. 2016; 25(7): 2000-22. PubMed Abstract | Publisher Full Text

8. Haneline MT, Rosner AL: The etiology of cervical artery dissection. J Chiropr Med. 2007; 6(3): 110-20. PubMed Abstract | Publisher Full Text | Free Full Text

9. Mann T, Refshauge KM: Causes of complications from cervical spine manipulation. Aust J Physiother. 2001; 47(4): 255-66. PubMed Abstract | Publisher Full Text

10. Biller J, Sacco RL, Albuquerque FC, et al: Cervical arterial dissections and association with cervical manipulative therapy: A statement for healthcare professionals from the American Heart Association/American Stroke Association. Stroke. 2014; 45(10): 3155-3174 PubMed Abstract | Publisher Full Text

11. Church EW, Sieg EP, Zalatimo O, et al:: Systematic Review and Meta-analysis of Chiropractic Care and Cervical Artery Dissection: No Evidence for Causation. Cureus. 2016; 8(2): e498. PubMed Abstract | Publisher Full Text | Free Full Text 
12. Krauss J, Creighton D, Ely JD, et al:: The immediate effects of upper thoracic translatoric spinal manipulation on cervical pain and range of motion: a randomized clinical trial. J Man Manip Ther. 2008; 16(2): 93-9. PubMed Abstract | Publisher Full Text | Free Full Text

13. Huisman PA, Speksnijder CM, de Wijer A: The effect of thoracic spine manipulation on pain and disability in patients with non-specific neck pain: a systematic review. Disabil Rehabil. 2013; 35(20): 1677-85.

PubMed Abstract | Publisher Full Text

14. Walser RF, Meserve BB, Boucher TR: The effectiveness of thoracic spine manipulation for the management of musculoskeletal conditions: a systematic review and meta-analysis of randomized clinical trials. J Man Manip Ther. 2009; 17(4): 237-46.

PubMed Abstract | Publisher Full Text | Free Full Text

15. Cleland JA, Childs JD, McRae M, et al.: Immediate effects of thoracic manipulation in patients with neck pain: a randomized clinical trial. Man Ther 2005; 10(2): 127-35.

PubMed Abstract | Publisher Full Text

16. Suvarnnato T, Puntumetakul R, Kaber D, et al:: The effects of thoracic manipulation versus mobilization for chronic neck pain: a randomized controlled trial pilot study. J Phys Ther Sci. 2013; 25(7): 865-71. PubMed Abstract | Publisher Full Text | Free Full Text

17. Casanova-Méndez A, Oliva-Pascual-Vaca A, Rodriguez-Blanco C, et al:: Comparative short-term effects of two thoracic spinal manipulation techniques in subjects with chronic mechanical neck pain: a randomized controlled trial. Man Ther. 2014; 19(4): 331-7.

PubMed Abstract | Publisher Full Text

18. González-Iglesias J, Fernández-de-las-Peñas C, Cleland JA, et al:: Inclusion of thoracic spine thrust manipulation into an electro-therapy/thermal program for the management of patients with acute mechanical neck pain: a randomized clinical trial. Man Ther. 2009; 14(3): 306-13.

PubMed Abstract | Publisher Full Text

19. Salom-Moreno J, Ortega-Santiago R, Cleland JA, et al.: Immediate changes in neck pain intensity and widespread pressure pain sensitivity in patients with bilateral chronic mechanical neck pain: a randomized controlled trial of thoracic thrust manipulation vs non-thrust mobilization. J Manipulative Physiol Ther. 2014; 37(5): 312-9.

PubMed Abstract | Publisher Full Tex

20. Cross KM, Kuenze C, Grindstaff TL, et al:: Thoracic spine thrust manipulation improves pain, range of motion, and self-reported function in patients with mechanical neck pain: a systematic review. J Orthop Sports Phys Ther. 2011; 41(9): 633-42.

PubMed Abstract | Publisher Full Text

21. Cleland JA, Glynn P, Whitman JM, et al.: Short-term effects of thrust versus nonthrust mobilization/manipulation directed at the thoracic spine in patients with neck pain: a randomized clinical trial. Phys Ther. 2007; 87(4): 431-440.

PubMed Abstract | Publisher Full Text

22. Fernández-de-las-Peñas $\mathrm{C}$, Palomeque-del-Cerro L, Rodríguez-Blanco $\mathrm{C}$, et al:: Changes in neck pain and active range of motion after a single thoracic spine manipulation in subjects presenting with mechanical neck pain: a case series. J Manipulative Physiol Ther. 2007; 30(4): 312-20.

PubMed Abstract | Publisher Full Text

23. Puntumetakul $R$, Suvarnnato $T$, Werasirirat $P$, et al.: Acute effects of single and multiple level thoracic manipulations on chronic mechanical neck pain: a randomized controlled trial. Neuropsychiatr Dis Treat. 2015; 11: 137-44. PubMed Abstract | Publisher Full Text | Free Full Text

24. Kawchuk GN, Prasad NG, McLeod RC, et al.: Variability of force magnitude and force duration in manual and instrument-based manipulation techniques.

J Manipulative Physiol Ther. 2006; 29(8): 611-8.

PubMed Abstract | Publisher Full Tex

25. Colloca CJ, Keller TS, Black P, et al:: Comparison of mechanical force of manually assisted chiropractic adjusting instruments. $J$ Manipulative Physiol Ther. 2005; 28(6): 414-22.

PubMed Abstract | Publisher Full Text

26. Wood TG, Colloca CJ, Matthews R: A pilot randomized clinical trial on the relative effect of instrumental (MFMA) versus manual (HVLA) manipulation in the treatment of cervical spine dysfunction. J Manipulative Physiol Ther. 2001; 24(4): 260-71.

PubMed Abstract | Publisher Full Text

27. Shearar KA, Colloca CJ, White HL: A randomized clinical trial of manual versus mechanical force manipulation in the treatment of sacroiliac joint syndrome. J Manipulative Physiol Ther. 2005; 28(7): 493-501.

PubMed Abstract | Publisher Full Text

28. Herzog W: The biomechanics of spinal manipulation. J Bodyw Mov Ther. 2010; 14(3): 280-6.

PubMed Abstract | Publisher Full Text

29. Schneider MJ, Brach J, Irrgang JJ, et al.: Mechanical vs manual manipulation for low back pain: An observational cohort study. J Manipulative Physiol Ther. 2010; 33(3): 193-200.

PubMed Abstract | Publisher Full Text | Free Full Text

30. Langenfeld A, Humphreys BK, de Bie RA, et al: Effect of manual versus mechanically assisted manipulations of the thoracic spine in neck pain patients: study protocol of a randomized controlled trial. Trials. 2015; 16: 233. PubMed Abstract | Publisher Full Text | Free Full Text
31. Guzman J, Haldeman S, Carroll LJ, et al.: Clinical practice implications of the Bone and Joint Decade 2000-2010 Task Force on Neck Pain and Its Associated Disorders: from concepts and findings to recommendations. $J$ Manipulative Physiol Ther. 2009; 32(2 Suppl): S227-43.

PubMed Abstract | Publisher Full Text

32. Krauss JR, Evjenth O, Creighton D: Translatoric Spinal Manipulation for Physical Therapists. 1st edition. A Lakeview Media L.L.C. Publication; 2006. Reference Source

33. Colloca CJ: Neuromechanical Innovations: Impulse Adjusting System. 1st edition. Chandler, Arizona: Neuromechnical Innovations; 2012.

34. Jull GA, Falla D, Treleaven J, et al:: A therapeutic exercise approach for cervical disorders. In Grieves Mod Man Ther verterbral Column. 3rd edition. Edited by Boyling JD, Jull GA. Edinburgh, London, New York, Oxford, Philadelphia, St. Louis, Sydney, Toronto: Elsevier, Churchill, Livingston; 2004; 451-471. Reference Source

35. O'Leary S, Jull G, Kim M, et al.: Specificity in retraining craniocervical flexor muscle performance. J Orthop Sports Phys Ther. 2007; 37(1): 3-9. PubMed Abstract | Publisher Full Text

36. Price DD, McGrath PA, Rafii A, et al.: The validation of visual analogue scales as ratio scale measures for chronic and experimental pain. Pain. 1983; 17(1): 45-56.

PubMed Abstract | Publisher Full Text

37. Price DD, Bush FM, Long S, et al.: A comparison of pain measurement characteristics of mechanical visual analogue and simple numerical rating scales. Pain. 1994; 56(2): 217-226. PubMed Abstract | Publisher Full Text

38. DeLoach LJ, Higgins MS, Caplan AB, et al.: The visual analog scale in the immediate postoperative period: intrasubject variability and correlation with a numeric scale. Anesth Analg. 1998; 86(1): 102-106.

PubMed Abstract | Publisher Full Text

39. Williamson A, Hoggart B: Pain: a review of three commonly used pain rating scales. J Clin Nurs. 2005; 14(7): 798-804.

PubMed Abstract | Publisher Full Text

40. Swanenburg J, Humphreys K, Langenfeld A, et al:: Validity and reliability of a German version of the Neck Disability Index (NDI-G). Man Ther. 2014; 19(1): $52-58$.

PubMed Abstract | Publisher Full Text

41. Vernon H: The Neck Disability Index: state-of-the-art, 1991-2008. J Manipulative Physiol Ther. 2008; 31(7): 491-502.

PubMed Abstract | Publisher Full Text

42. Kim SH, Kim HJ, Lee SI, et al:: Comparing the psychometric properties of the EQ-5D-3L and EQ-5D-5L in cancer patients in Korea. Qual Life Res. 2012; 21(6): $1065-73$

PubMed Abstract | Publisher Full Text

43. Janssen MF, Pickard AS, Golicki D, et al.: Measurement properties of the EQ-5D-5L compared to the EQ-5D-3L across eight patient groups: a multi-country study. Qual Life Res. 2013; 22(7): 1717-27.

PubMed Abstract | Publisher Full Text | Free Full Text

44. Hurst $\mathrm{H}$, Bolton $\mathrm{J}$ : Assessing the clinical significance of change scores recorded on subjective outcome measures. J Manipulative Physiol Ther. 2004; 27(1): 26-35.

PubMed Abstract | Publisher Full Text

45. Pool JJ, Ostelo RW, Hoving JL, et al.: Minimal clinically important change of the Neck Disability Index and the Numerical Rating Scale for patients with neck pain. Spine (Phila Pa 1976). 2007; 32(26): 3047-3051. PubMed Abstract | Publisher Full Text

46. Cleland JA, Childs JD, Whitman JM: Psychometric properties of the Neck Disability Index and Numeric Pain Rating Scale in patients with mechanical neck pain. Arch Phys Med Rehabil. 2008; 89(1): 69-74.

PubMed Abstract | Publisher Full Text

47. Schuller W, Ostelo RW, Janssen R, et al:: The influence of study population and definition of improvement on the smallest detectable change and the minimal important change of the neck disability index. Health Qual Life Outcomes. 2014; 12: 53.

PubMed Abstract | Publisher Full Text | Free Full Text

48. Young BA, Walker MJ, Strunce JB, et al:: Responsiveness of the Neck Disability Index in patients with mechanical neck disorders. Spine J. 2009; 9(10): 802-808. PublMed Abstract | Publisher Full Text

49. Pereira M, Cruz EB, Domingues L, et al.: Responsiveness and Interpretability of the Portuguese Version of the Neck Disability Index in Patients With Chronic Neck Pain Undergoing Physiotherapy. Spine (Phila Pa 1976). 2015; 1 PubMed Abstract | Publisher Full Text

50. Swanenburg J, Gruber C, Brunner F, et al:: Patients' and therapists' perception of change following physiotherapy in an orthopedic hospital's outpatient clinic. Physiother Theory Pract. 2015; 31(4): 293-8.

PubMed Abstract | Publisher Full Text

51. Farrar JT, Young JP Jr, LaMoreaux L, et al.: Clinical importance of changes in chronic pain intensity measured on an 11-point numerical pain rating scale. Pain. 2001; 94(2): 149-158.

PubMed Abstract | Publisher Full Text

52. Richardson A: The health diary: an examination of its use as a data collection method. J Adv Nurs. 1994; 19(4): 782-791. PubMed Abstract | Publisher Full Text 
53. Takeuchi A, Mamorita N, Sakai F, et al.: Development of a comprehensive medical recorder on a cellphone. Comput Methods Programs Biomed. 2010; 97(1): 28-38.

PubMed Abstract | Publisher Full Text

54. Huggins T, Boras AL, Gleberzon BJ, et al:: Clinical effectiveness of the activator adjusting instrument in the management of musculoskeletal disorders: a systematic review of the literature. J Can Chiropr Assoc. 2012; 56(1): 49-57. PubMed Abstract | Free Full Text

55. Cleland JA, Childs JD, Fritz JM, et al.: Development of a clinical prediction rule for guiding treatment of a subgroup of patients with neck pain: use of thoracic spine manipulation, exercise, and patient education. Phys Ther. 2007; 87(1): 9-23. PubMed Abstract | Publisher Full Text

56. Haldeman S, Kohlbeck FJ, McGregor M: Unpredictability of cerebrovascular ischemia associated with cervical spine manipulation therapy: a review of sixty-four cases after cervical spine manipulation. Spine (Phila Pa 1976). 2002; 27(1): 49-55.

PubMed Abstract

57. Sweeney A, Doody C: Manual therapy for the cervical spine and reported adverse effects: a survey of Irish manipulative physiotherapists. Man Ther. 2010; 15(1): 32-6.

PubMed Abstract | Publisher Full Text

58. Thiel HW, Bolton JE, Docherty S, et al: Safety of chiropractic manipulation of the cervical spine: a prospective national survey. Spine (Phila Pa 1976). 2007; 32(21): 2375-8; discussion 2379

32(21): 2375-8; discussion 2379.
PubMed Abstract | Publisher Full Text

59. Miley ML, Wellik KE, Wingerchuk DM, et al:: Does cervical manipulative therapy cause vertebral artery dissection and stroke? Neurologist. 2008; 14(1):

66-73.

PubMed Abstract | Publisher Full Text
60. Thomas LC, Rivett DA, Attia JR, et al:: Risk factors and clinical features of craniocervical arterial dissection. Man Ther. 2011; 16(4): 351-6. PubMed Abstract | Publisher Full Text

61. Cassidy JD, Boyle E, Côté $P$, et al.: Risk of vertebrobasilar stroke and chiropractic care: results of a population-based case-control and casecrossover study. Spine (Phila Pa 1976). 2008; 36: 92; author reply 92.

62. Marx P, Püschmann $\mathrm{H}$, Haferkamp $\mathrm{G}$, et al.: [Manipulative treatment of the cervical spine and stroke]. Fortschr Neurol Psychiatr. 2009; 77(2): 83-90. PubMed Abstract | Publisher Full Text

63. Murphy DR: Current understanding of the relationship between cervical manipulation and stroke: what does it mean for the chiropractic profession? Chiropr Osteopat. 2010; 18: 22.

PubMed Abstract | Publisher Full Text | Free Full Text

64. Noordzij M, Tripepi G, Dekker FW, et al:: Sample size calculations: basic principles and common pitfalls. Nephrol Dial Transplant. 2010; 25(5): 1388-93. PubMed Abstract | Publisher Full Text

65. Kelly AM: The minimum clinically significant difference in visual analogue scale pain score does not differ with severity of pain. Emerg Med J. 2001; 18(3): 205-7. PubMed Abstract | Publisher Full Text | Free Full Text

66. Svedmark $\AA$, Djupsjöbacka M, Häger C, et al.: Is tailored treatment superior to non-tailored treatment for pain and disability in women with non-specific neck pain? A randomized controlled trial. BMC Musculoskelet Disord. 2016; 17(1): 408 PubMed Abstract | Publisher Full Text | Free Full Text

67. Langenfeld A, Humphreys BK, de Bie RA, et al:: Dataset 1 in: Comparing manual and mechanically assisted manipulations of the thoracic spine in neck pain patients: A pilot study. F1000Research. 2018

Data Source 


\section{Peer review discontinued Peer review at F1000Research is author-driven. currently no reviewers are being invited. What does this mean?}

\section{Version 1}

Reviewer Report 20 July 2018

https://doi.org/10.5256/f1000research.14977.r36000

(C) 2018 Verhagen A. This is an open access peer review report distributed under the terms of the Creative Commons Attribution License, which permits unrestricted use, distribution, and reproduction in any medium, provided the original work is properly cited.

\section{Arianne P. Verhagen}

School of Physiotherapy, Graduate School of Health, University of Technology Sydney, Sydney, NSW, Australia

Thank you for asking me to review this manuscript. Although this RCTs is of very low power, I understand the need to publish it as it might be a kind of research waste not to publish it. Nevertheless I have a couple of comments:

1. this study aims to evaluate the difference, or maybe the absence of difference, between two forms of manual therapy. As these concern two active treatments it is essential to know whether the study aims at evaluating superiority of one intervention over another or aims at evaluating equivalence. The method is quite unclear about that, but I think this needs to be clear from the objective, please revise.

2. This study clearly aimed at including more people that they actually did. This information needs to be presented. Furthermore the reader needs to know where patient recruitment was performed, during which period and what actions have been done to improve recruitment. Please add this information.

3. In the result section (in the abstract as well as in the main text) the authors mix within group differences and between group differences. Any mention of within group differences are irrelevant as the study is set up to evaluate between group differences. I would strongly recommend to take out all mention of within group improvements as this is misleading. 4. In the discussion the authors mention as one of the main finding an improvement of all patients. This is a logical finding as, apart from one patient, all had acute neck pain, so natural course will probably be responsible for the improvement. This needs to be discussed!

5. The conclusions are way too firm given the low number of included people. The main conclusion (i.e. the first sentence) is even incorrect as all people improved, but we cannot state that manipulations can be held responsible for that, as I believe this is due to natural course. As long as there is not a no treatment group in this RCT one cannot make such a conclusion.

\section{Is the work clearly and accurately presented and does it cite the current literature?} Yes 
Is the study design appropriate and is the work technically sound?

Yes

Are sufficient details of methods and analysis provided to allow replication by others? Partly

If applicable, is the statistical analysis and its interpretation appropriate? Partly

Are all the source data underlying the results available to ensure full reproducibility? Yes

Are the conclusions drawn adequately supported by the results?

Partly

Competing Interests: No competing interests were disclosed.

I confirm that I have read this submission and believe that I have an appropriate level of expertise to state that I do not consider it to be of an acceptable scientific standard, for reasons outlined above.

The benefits of publishing with F1000Research:

- Your article is published within days, with no editorial bias

- You can publish traditional articles, null/negative results, case reports, data notes and more

- The peer review process is transparent and collaborative

- Your article is indexed in PubMed after passing peer review

- Dedicated customer support at every stage

For pre-submission enquiries, contact research@f1000.com 